\title{
Pesquisas sobre formação de professores para a educação superior na anped (2011-2017)
}

\author{
Research about teacher education for higher education at anped (2011-2017)
}

\author{
Giovanna Ofretorio de Oliveira Martin Franchi ${ }^{1}$
}

Márcia de Souza Hobold ${ }^{2}$

\section{Resumo}

O artigo em questão busca fomentar a discussão em relação a formação de professores para a Educação Superior a partir de publicações de pesquisa na área da Pós-Graduação, e, assim, oferecer subsídios para o aprofundamento de pesquisas na área da Educação, em especial, na formação de professores para o Ensino Superior. O objetivo geral do estudo consistiu em mapear e analisar as publicações na área da Educação, especificamente as pesquisas relacionadas ao campo da Formação de Professores para o Ensino Superior, divulgadas por meio de trabalhos completos publicados nos anais das reuniões nacionais da Associação Nacional de Pós-Graduação e Pesquisa em Educação - ANPEd, corroborando para o estado do conhecimento sobre Formação de Professores para o Ensino Superior referentes ao período de 2011 a 2017, direcionando o olhar para o Grupo de Trabalho (GT) 08 - Formação de Professores. A pesquisa de cunho qualitativo valeu-se da pesquisa análise documental (BOGDAN; BICKLEN, 1997; CELLARD, 2008) para coleta dos dados e da análise de conteúdo (BARDIN, 2011; MINAYO, 2010) para analisar os dados selecionados. A partir da temática Formação de Professores para a Educação Superior, os dados revelam que as pesquisas relacionadas ao campo da formação de professores para atuar na educação superior, quanto relacionados à formação continuada para docentes na educação superior ainda constituem incipiente em relação aos demais temas abordados no referido GT08.

Palavras-chave: Formação de professores; Ensino superior; Docência; GT 08 Formação de Professores; ANPEd.

\footnotetext{
${ }^{1}$ Mestre em Educação pela Faculdade de Filosofia e Letras de Ribeirão Preto- Universidade de São Paulo. Doutoranda em Educação na Pós Graduaçâo em Educação da Universidade Federal de Santa Catarina. Membro do Grupo de Estudos e Pesquisas: Formação de Professores e Práticas de Ensino - FOPPE. E-mail: gfranchi_m@yahoo.com.br

${ }^{2}$ Pós-Doutoramento em Educação na PUC SP, com bolsa do CNPq-PDJ. Doutora em Educação pela PUC SP. Atualmente é Professora da Universidade Federal de Santa Catarina (UFSC), vinculada ao Programa de PósGraduação em Educação - PPGE e ao Departamento de Metodologia de Ensino - MEN, do Centro de Ciências da Educação (MEN/CED/UFSC). É líder do Grupo de Estudos e Pesquisas: Formação de Professores e Práticas de Ensino - FOPPE; membro da Rede Interinstitucional de Pesquisas sobre a Formação e as Práticas Docentes RIPEFOR; integrante do Grupo de Trabalho (GT 8) de Formação de Professores da ANPEd Nacional; e, membro do Núcleo de Estudos e Pesquisas sobre o Desenvolvimento Profissional Docente, da PUC SP. E-mail mhobold@gmail.com
} 


\begin{abstract}
This article in question seeks to encourage discussion about teacher education for higher education from research publications in the Post graduate area, and thus, to offer subsidies for the deepen of research in the area of education, especially in the teachers education for higher education.. The general objective of the study was to map and analyze the publications in the area of Education specifically research related to the field of the Teacher Education for Higher Education, published through complete works in a given scientific event, of national notoriety. The study collected data from the studies presented at national meetings of the National Association of post-graduation and research in Education - Anped, corroborating for the state of knowledge on Teacher Education for Higher Education for the year 2010, 2011, 2012, 2015 and 2017, directing the look at Working Groups (WG) 08 - Teacher Education. The research of qualitative nature used the research documentary analysis (BOGDAN; BICKLEN, 1997; CELLARD, 2008) for data collection and content analysis (BARDIN, 2011; MINAYO, 2010) to analyze the selected data. Based on the theme of teacher education for higher education the data reveal that research related to the field teacher education to act in higher education, and related to continuing education for teachers in higher education are still incipient concerning the other topics addressed in the relation to the other topics addressed in the GT08
\end{abstract}

Keywords: Teacher education; Higher education; Teaching; GT 08 Teacher education; ANPEd.

\title{
Introdução
}

Este estudo e as questões apresentadas relacionam-se à formação docente para a Educação Superior. A Lei 9394/96, em seu artigo 66, afirma que a preparação para o exercício da docência no magistério superior se dará em nível de pós-graduação, ocorrendo prioritariamente em programas de mestrado e doutorado (BRASIL, 1996). Considerando as discussões em relação ao termo "preparação" para a docência contida na referida lei, assim como outros estudos, partimos do entendimento de que, para além de preparar, é relevante formar o pós-graduando para atuar como docente em Instituições de Educação Superior (IES). Valemo-nos ainda da definição de Instituições de Educação Superior contidas na Lei 9394/96, em seu artigo 52, que as definem como Instituições pluridisciplinares, de formação dos quadros profissionais de nível superior, que possuem dentre outras características "a 
produção intelectual institucionalizada mediante o estudo sistemático dos temas e problemas mais relevantes, tanto do ponto de vista científico e cultural quanto regional e nacional"(BRASIL, 1996).

É relevante que a formação docente para este nível de ensino seja pensada a partir da complexidade desta ação. A docência na Educação é ação complexa, pois exige saberes de diferentes naturezas "alicerçados tanto na cultura em que o professor se constitui como na compreensão teórica que lhe possibilita justificar suas opções” (CUNHA, 2008b, p. 20). Requer vislumbrar no sujeito em formação para a docência na Educação Superior não apenas a aquisição de conhecimento da área específica, mas também da área pedagógica, bem como considerar as questões relativas à própria IES que atuará. É esperado do docente uma compreensão do espaço em que sua profissão está situada, os sujeitos nela envolvidos, os dilemas e os desafios inerentes ao seu desenvolvimento.

No conjunto das Instituições de Educação Superior, a Universidade se caracteriza por desenvolver o ensino, a pesquisa e a extensão. As pesquisas científicas desenvolvidas no âmbito das Universidades e demais instituições de Educação Superior, a partir de projetos e grupos de pesquisas diversos, sinalizam os temas mais recorrentes que perpassam as indagações sobre o próprio conhecimento da área, a sociedade e o momento histórico. Neste sentido, inquietou-nos questões sobre os temas mais recorrentes e abordados em relação à formação docente para a Educação Superior, materializadas em pesquisas apresentadas em evento científico direcionado ao público da Pós-Graduação em Educação. Para tal, direcionamos nosso olhar sobre as produções científicas apresentadas no Grupo de Trabalho Formação de professores - (GT08), da ANPEd - Associação Nacional de Pós-Graduação e Pesquisa em Educação, no período de 2011 a 2017, no que diz respeito à pesquisa sobre formação docente para o Educação Superior.

A relevância em estudar os trabalhos completos apresentados na ANPEd ${ }^{3}$ incide, pois, na importância e singularidade desta associação tanto em relação à sua atuação em nível nacional, quando em seu papel atuante, decisivo e comprometido às principais lutas pela universalização e desenvolvimento da educação no Brasil. A contribuição em fomentar a investigação e fortalecer a formação na pós-graduação em educação promove também o debate na área, constituindo-se, pois, um espaço ímpar no aperfeiçoamento de professores, pesquisadores, estudantes e gestores da área.

\footnotetext{
${ }^{3}$ http://anped.org.br/sobre-anped
} 
No contex to da ANPEd ${ }^{4}$ o GT08 foi criado inicialmente como GT Licenciaturas, sob a coordenação da professora Míriam Krasilchik, iniciando suas atividades na $7^{\mathrm{a}}$ Reunião Anual da ANPEd, em 1984, com o intuito de tratar das questões relacionadas ao momento histórico em que os debates questionavam os modelos então propostos para a formação e professores. No período de 1992 a 1993, com a evolução dos temas de pesquisa no GT Licenciaturas, buscando a articulação entre a formação, o trabalho e a identidade docente, o mesmo passou então a ser denominado Formação de Professores, apresentando uma perspectiva mais ampla e plural em relação ao seu objeto global do campo de pesquisa.

\section{Os caminhos da pesquisa}

A pesquisa de cunho qualitativo valeu-se da pesquisa análise documental (BOGDAN; BICKLEN, 1997; CELLARD, 2008) para coleta dos dados e da análise de conteúdo (BARDIN, 2011; MINAYO, 2010). O corpus da pesquisa foi formado pelos resumos dos trabalhos completos apresentados no referido GT08 - Formação de professores. Partimos do pressuposto de Severino (2007, p. 208-209), para o qual os resumos técnicos de trabalhos científicos possuem "[...] a finalidade específica de passar ao leitor uma ideia completa do teor do documento analisado", fornecendo, pois, "todas as informações necessárias para que o leitor/pesquisador possa fazer uma primeira avaliação do texto analisado e dar-se conta de suas eventuais contribuições". Neste sentido, foram analisados 115 resumos de trabalhos completos apresentados no GT08 - Formação de professores, no período de 2011 a 2017.

Considerando a análise temática, a partir da análise de conteúdo (BARDIN, 2011) foi definido o tema Formação docente para a Educação Superior para coleta e análise dos dados. Entre os 115 resumos de trabalhos completos analisados, a temática Formação docente para a Educação Superior está presente em 11 resumos, ou seja, 9,6\% dos trabalhos apresentados entre os anos de 2011 a 2017 no GT08 - Formação de professores da ANPEd referem-se à docência para a Educação Superior. Ressaltamos que no ano de 2017 não houve trabalhos completos relacionado ao tema. Tendo em vista o baixo número de pesquisas relacionada à área da docência para a Educação Superior em relação as demais temáticas abordadas no GT08, no período citado, tornou-se relevante apresentar dados

\footnotetext{
${ }^{4}$ http://anped.org.br/grupos-de-trabalho/gt08-forma\%C3\%A7\%C3\%A3o-de-professores
} 


\section{QO DEVIR EDUCAÇÃO \\ ISSN: 2526-849X}

relacionados aos trabalhos completos voltadas para a docência no Educação Superior. Para tal, direcionamos a análise aos trabalhos completos apresentados no evento. A seguir apresentamos a tabela 1 indicando o número de trabalhos relacionados ao tema Formação docente para Educação Superior nas Reuniões da ANPEd no período:

Tabela 1 - Trabalhos sobre o tema Formação de Professores para a Educação Superior Florianópolis - 2019.

\begin{tabular}{ccccc}
\hline Reuniões da ANPEd & Ano & Demais temas & $\begin{array}{c}\text { Formação docente } \\
\text { para a Educação } \\
\text { Superior }\end{array}$ & Total \\
\hline $34^{\circ}$ & 2011 & 19 & 2 & 21 \\
$35^{\circ}$ & 2012 & 19 & 3 & 22 \\
$36^{\circ}$ & 2013 & 15 & 3 & 18 \\
$37^{\circ}$ & 2015 & 31 & 3 & 34 \\
$38^{\circ}$ & 2017 & 20 & 0 & 20 \\
\hline Total & & 104 & 11 & 115 \\
\hline
\end{tabular}

No tema Formação docente para a Educação Superior apresentam-se 11 trabalhos relacionado à: professoralidade, profissionalidade, desenvolvimento profissional, docência universitária, formação continuada, formação docente para a Educação Superior, pedagogia Universitária, necessidades formativas de docentes iniciantes e formação pedagógica na pósgraduação. Para a análise e coleta dos dados valemo-nos das seguintes categorias de análise (BARDIN, 2001): objeto tratado (objeto de estudo), referenciais teóricos de apoio, procedimentos metodológicos, conclusões e resultados. Conforme ressalta Severino (2007, dentre os principais dados que os resumos de trabalhos científicos devem conter, escolhemos os os dados citados anteriormente, considerando-os como categorias para a análise dos dados.

Indicamos ainda que, apesar destas categorias serem pensadas para a análise dos resumos dos trabalhos completos, estas permaneceram também como categorias para a análise do texto integral dos trabalhos completos, pois compreendemos que não seria necessário modificar as categorias, pois as mesmas cumprem o objetivo proposto em identificar determinados dados relevantes destes trabalhos. A análise a seguir indica os trabalhos apresentados em cada Reunião da ANPEd.

Revista Devir Educação, Lavras, vol.3, n.2, p.53-74 jul./dez., 2019. 
Na 34 Reunião da ANPEd realizado em 2011, 2 dos 19 trabalhos completos estão inseridos na temática Formação docente para a Educação Superior.

O trabalho intitulado Atividades de produção da docência: a professoralidade Universitaria, de Powaczuk e Bolzan (2011) apresenta como objeto de estudo as atividades de ensino e atividades de formação, consideradas imbricadas e presentes nos processos envolvidos tanto na produção quanto na constituição da professoralidade e da docência universitária. Os referenciais teóricos de apoio versam sobre; se apoiam no aporte teórico de: sobre o conceito de atividade - Vygotski (1989, 2003, 2007) e Leontiev (1984, 1988, 1989), Davidov e Shuare (1987); abordagem qualitativa de cunho sociocultural - Clandinin e Conelly (1995); Vygostki (2007), Baktin (1992, 2006). Em relação ao contexto da docência no Ensino Superior, da Pedagogia Universitária, e os dilemas que nelas se encontram, apontam os estudos de Isaia (2003, 2004, 2005, 2006), Morosine (2001, 2003), Maseto (2005), Pimenta e Anastásiou (2002) e Cunha (2006, 2008, 2010). O conceito de formação e compreendido a partir de Ferry (2004); sobre a prática docente e o trabalho docente dialogam com Tardif (2007), Masetto (2005). Cunha (2008) e Zabalza (2004) dialogam em relação à docência na universidade e seu contexto. Sobre os procedimentos metodológicos, se destaca a investigação de abordagem qualitativa de cunho social, com base em Clandinin e Conelly (1995); Vygostki (2007), Baktin (1992, 2006), tendo como foco as narrativas de professores bacharéis e licenciados atuantes no Ensino Superior de uma Universidade Federal do interior do estado do Rio Grande do Sul. O trabalho apresentou as seguintes conclusões e resultados: as considerações sobre a atividades de ensino e atividade formativa, a partir da professoralidade universitária destacam as fragilidades no tratamento da formação do professor deste nível de ensino. A definição de três momentos de tensão que vem compondo a contextura da professoralidade universitária, quais sejam: 1) a relação entre ensino e formação para a docência, constituídas pela professoralidade universitária tensionada; a priorização da pesquisa e domínio do conteúdo específico em detrimento aos processos de pensamento necessários ao planejamento e a ação docente para esse nível de ensino; hierarquização entre o domínio do conhecimento específico e o domínio conhecimento pedagógico; 2) A relação entre conhecimento específico e conhecimento pedagógico, que permitem destacar o predomínio do conhecimento específico sobre o conhecimento pedagógico, em que a superação deste ideário ultrapassa iniciativas individuais, envolvendo o coletivo de professores e instituições de ensino superior; 3) A relação entre o coletivo e o 
individual, onde observa-se um predomínio da responsabilidade individual sobre a formação para a docência neste nível de ensino, em contrapartida o desenvolvimento profissional docente não pode ser pensado em uma perspectiva individual, necessita ser assumido coletivamente e institucionalmente, integrando processos voltados à melhoria das condições do trabalho docente e de ações transformadoras do ensino. O trabalho analisado indica que a produção da professoralidade universitária precisa se relacionar a um desenvolvimento profissional consistente, em que espaços organizados institucionalmente possibilitem aos professores deste nível de ensino espaços que contribuam para a troca de experiências e conhecimentos.

Em relação ao trabalho intitulado Docência Universitária e o Ensino Superior: análise de uma experiência formadora, de Oliveira (2011), não foi possível o acesso ao texto integral, por isso apresentamos os principais dados a partir do resumo do trabalho apresentado na $34^{\circ}$ Reunião da ANPEd. Apresenta como objeto de estudo o conhecimento das significações dos professores universitários em relação ao seu papel docente e seu processo formativo, a partir de um convênio Brasil e Portugal, de docentes que fazem parte do Programa Institucional de Formação e Desenvolvimento profissional de Docentes e Gestores CICLUS. Os referenciais teóricos de apoio relacionam-se a abordagem teóricametodológica História de Vida. É uma pesquisa de cunho qualitativo, em que os procedimentos metodológicos versam sobre a trajetória profissional e os processos formativos dos docentes que fizeram parte do Programa CICLUS. As conclusões e resultados não foram diretamente identificadas, porém o texto indica que a investigação/formação vem produzindo resultados sobre os processos de ensino aprendizagem na docência no ensino superior através de seus participantes do programa CICLUS oriundos de diferentes áreas de conhecimento.

Na $35^{\circ}$ Reunião da ANPEd realizado em 2012, 3 dos 22 trabalhos completos estão inseridos na temática Formação docente para a Educação Superior

O trabalho intitulado Aprender a ensinar, construir identidade e profissionalidade docente no contexto da universidade: uma realidade possível, de Rocha e Aguiar (2012) apresenta como objeto de estudo entender o professor a partir das suas necessidades em relação aos processos formativos e aos aspectos profissionais que interferem e dificultam o seu saber docente. Os referenciais teóricos de apoio versam sobre: contexto da universidade sobre práticas conservadoras Cunha (1998, 2007); Cordeiro (2006); Melo (2007); Cordeiro e 
Melo (2008); educação bancária Freire (1997); o professor universitário - Cunha (2004); história da universidade brasileira e a organização curricular - Darcy Ribeiro (1975); formação específica para a docência no contexto histórico da universidade - Kessler (2002); conceito de ensinar - Roldão (2005) e Freire (1997), Tardif (2002), Gage (1977); a sociedade e o professor - Lawn (1991); o docente do Ensino Superior - Cunha (2001); os professores, seus saberes e trajetória profissional - Tardif (2002), Charlot (2000) e Gauthier (1998); conhecimento pedagógico nos processos formativos- Shulman (1986); trabalho do professor e desenvolvimento profissional - Nóvoa (1992, 2009); Formação de professores: Nóvoa (2009), Feiman (1990), García (1999), Sacristán (1990), Schön (2000), Veiga (1991, 1993, 2002, 2010); identidade docente - Nóvoa (1992) e Pimenta (2002); profissionalidade docente Sacristán (1990), Paganini da Silva (2006), Roldão (2005), Dubar (1987); aprender a ensinar e aula - Pimenta e Anastasiou (2002), perspectiva interdisciplinar - Behrens (2007). Os procedimentos metodológicos versaram sobre a abordagem qualitativa - Minayo (2000) e a análise conteúdo - Bardin (2002), e valem-se da entrevista semiestruturada. Os sujeitos da pesquisa foram quatro docentes que lecionam nos cursos de formação de professore, de diferentes áreas do conhecimento. As conclusões e resultados indicam que apesar de os professores não possuírem formação específica para atuar na universidade, estes desenvolvem suas aulas de maneira a promover aprendizagens, e estes processos formativos são orientados por uma prática docente fundada na experiência, ou mesmo na reprodução da própria experiência. A pesquisa revela lacunas existentes na formação deste professor, bem como o reconhecimento da necessidade de formação continuada que possibilitem o distanciamento dos modelos reproduzidos dos seus professores e proporcione ressignificação de suas práticas, construção de identidade e de saberes da profissionalidade docente.

O trabalho intitulado Docência Universitária na Pós-Graduação: situando efeitos da Avaliação da Capes na Profissionalidade, de Ferraz e Melo (2012) apresenta como objeto de estudo a compreensão da profissionalidade docente a partir do mapeando de aspectos inerentes aos saberes e competências necessários aos docentes universitários em sua atividade profissional, tendo em vista a influência da avaliação da CAPES, visando a reconfiguração da docência universitária na pós-graduação. Os referenciais teóricos de apoio estão relacionados a Universidade, Política educacional e configuração da docência e versam sobre os autores: modelos, concepções e características da Universidade - Cunha, L (2000), Sguissardi (2004, 2006, 2008), Castanho (2000), Durham et al. (1987); Oliveira (2003), 
Catani e Oliveira (2002), Dourado (2002), Silva Jr e Sguissardi (2001), Trindade (1999); problemática da universidade brasileira - Fávero (1980), Cunha, L (2000); implantação da pós-graduação - Moraes e Kuenzer (2005); teoria do ciclo de políticas - Ball (1994), Bowe, Ball e Gold (1992); conceito de recontextualização - Bernstein (1996); dinâmica de Política e docência ampliada - Ball (2005), Bernstein (1996), Lopes (2005); docência universitária Tardif e Lessard (2005); docência como relações compartilhadas - Melo (2008); contexto do capitalismo e da globalização - Santos (2002), Ianni (1996); cultura da performatividade Ball, (2001, 2005); práticas de avaliação na pós-graduação - Dias Sobrinho (2003), Sguissardi (2008); Cunha (2005); hibridismo na docência - Lopes (2005); concepção de docência Cunha (2005); profissionalização na e da atividade - Bourdoncle (2000). Em relação aos procedimentos metodológicos foi utilizada a entrevista com os sujeitos da pesquisa professores universitários que atuam na pós-graduação em educação. Análise dos Planos Nacionais de Pós-Graduação e fichas de avaliação da CAPES, com o aporte teórico de Minayo (2008), Bardin (2011), categorias de recontextualização - Bernstein (1996, 2003), hibridismo - Lopes (2005), teoria do ciclo de políticas - Ball (1992, 1994). As conclusões e resultados indicam algumas tensões do processo de configuração da profissionalidade docente no ensino superior, no contexto da avaliação da pós-graduação, e a relação entre esta configuração e as influências individuais, institucionais e políticas. As autoras indicam também que é possível o aprimoramento dos "fazeres" desses docentes a partir de saberes construídos coletivamente, constituindo uma teia de relações que favorece a construção e permanente atualização de conhecimentos que são indispensáveis para o professor se mover no movimento de configuração de sua profissionalidade à luz de seus princípios. A influência da política de avaliação na configuração da profissionalidade docente, a partir do paradigma da docência performativa, segundo as autoras, conduz os professores a fazerem um esforço para sobreviver individualmente nos programas, manter o quantitativo da produção e desenvolver competências para a atividade de pesquisa, possibilitando redimensionar a própria concepção de profissionalidade; reafirmar a importância de uma necessária responsabilização institucional e individual mais efetiva com a docência; o necessário enfrentamento de desafios na (re)construção do "ser docente" diante das novas exigências éticas postas à profissionalização e ao exercício docente; ambivalência como marca da configuração da profissionalidade docente na pós-graduação; a necessidade de se repensar o modelo de avaliação no sentido de valorizar a diversidade de atividades dos docentes. Para as 
autoras, ao conceber o contexto da prática como espaço de ressignificação, observa-se que a política de avaliação, em certa medida, reconfigura a docência, e a docência também tem o poder de reconfigurar a política de avaliação.

O trabalho intitulado Formar ou preparar para a docência no ensino superior? eis a questão, de Campos (2012), possui como objeto de estudo a discussão da docência no ensino superior e sua consequente necessidade de formação pedagógica a partir de dois eixos fundamentais: a preparação ou a formação para a docência na pós-graduação stricto sensu. Os referenciais teóricos de apoio versam sobre: teoria das representações e o método genealógico propostos - Lefebvre (1983); a docência - Arroyo (2000), docência na Educação Superior - Cunha (2006, 2008); trabalho docente no ensino superior - Zabalza (2004); disciplina na pós-graduação - Pimenta e Anastasiou (2002), Morosini (2000); formação do docente universitário - Veiga (2006), Pimenta e Anastasiou (2010); sobre o ensino e o processo de ensinar - Freire (1996), Anastasiou e Alves (2003), Cunha (2006). Em relação aos procedimentos metodológicos a pesquisa de cunho qualitativo utilizou como instrumentos para coleta de dados: questionário, entrevista e observação das atividades docentes. Aplicaram 3.081 questionários enviados, dos quais 980 foram respondidos e entrevistaram 40 pós-graduandos. As conclusões e resultados indicam a existência de um hiato entre o concebido e o vivido pelos pós-graduandos em relação à docência, tanto os que têm experiência como docentes no ensino superior, quanto aqueles que ainda não são professores; a pouca importância direcionada à formação pedagógica nos cursos de pósgraduação stricto sensu, tanto no âmbito legal quanto na dimensão histórica e cultural, a formação da docência foi substituída pela preparação para a docência no ensino superior. Segunda a autora a preparação não acontece de fato, pois os conhecimentos pedagógicos específicos à formação para a docência do ensino superior não estão presentes nos cursos de pós-graduação. E ainda se preconiza uma preparação aligeirada, em que a formação para a docência ainda acontece de forma tácita e artesanal, baseada no dom, na vocação, nas experiências do senso comum discente, na lógica "de quem sabe ensina". Os saberes da experiência discente são mais valorizados em detrimento aos conhecimentos específicos da docência. A análise indica ainda a fragilidade na construção e constituição da identidade docente no ensino superior. Indica que há algumas iniciativas pontuais nesta direção, mas ainda faltam políticas educacionais consistentes que de fato valorizem a formação inicial e continuada do docente do ensino superior. 
Na 36 ${ }^{\circ}$ Reunião da ANPEd realizado em 2013, 3 dos 28 trabalhos completos estão inseridos na temática Formação docente para a Educação Superior.

O trabalho intitulado Análise de necessidades formativas de docentes ingressantes numa universidade pública, de Lima (2013), indica como objeto de estudo as necessidades formativas de docentes ingressantes, no contexto da proposta de um programa de formação continuada em cursos de graduação de uma Universidade Pública, especialmente dirigido aos recém-contratados. Os referenciais teóricos de apoio consistem: na necessidade de ancorar as políticas institucionais na elucidação de dados sobre a formação e as necessidades formativas - Roegiers, Wouters e Gérard (1992); necessidades de formação - Lang (s/d); dimensão de objetividade e subjetividade - Benedito, Imbernón e Félez (2001); função da docência na universidade e formação docente para a universidade - Cunha e Zanchet (2010); o professor universitário - Estepa et al. (2005). Em relação aos procedimentos metodológicos, foi utilizado o questionário com perguntas fechadas e abertas e a solicitação que os docentes criassem uma imagem para representar a experiência de ensino na universidade. $\mathrm{O}$ questionário foi aplicado a 253 docentes, dos quais 99 responderam. As conclusões e resultados indicam a existência de muitos docentes cujo interesse se volta ao ensino de graduação, sendo contrário à idéia generalizada de que hoje o interesse docente volta-se apenas para pesquisa. Sinaliza a relevância das instituições em apostar na oferta de apoio pedagógico sistemático, por meio de políticas e práticas de formação continuada no local de trabalho. Indica que estas políticas e práticas sejam direcionadas tanto às necessidades de formação por parte dos docentes, bem como as postas pela universidade e pelo mundo atual e futuro, bem como a superação da visão técnica que ainda prevalece nas percepções dos docentes, acrescentando nestas, visões igualmente importantes como as cultural, a ética, a estética, a tecnológica, a ambiental etc., na perspectiva de uma universidade para todos e de um mundo no qual todos tenham lugar.

O trabalho intitulado Pedagogia Universitária: construções possíveis nas Diferentes áreas de conhecimento, de Isaia e Maciel (2013), apresenta como objeto de estudo as áreas específicas de conhecimento dos professores de uma instituição pública, e se estas podem influir na construção dos movimentos da docência na Educação Superior (MDES). Os referenciais teóricos de apoio versam sobre: conceito de objeto - Abbagnano (1970); saber Gauthier et al. (1998); relação entre o conhecimento e os saberes - Gamboa (2009); identidade dos contrários - Cheptulin (1982); conhecimento científico - Gamboa (2009); 
constituição da docência a partir de narrativas, narrativas e linguagem - Habermas (1987a, 1987b), Ricoeur (1987), Vygotski (1993); vidas profissionais como objeto de autorreflexão Huberman (1998), Mcewan (1998); Isaia (2005, 2008); desenvolvimento profissional Marcelo Garcia (1999); trajetória docente - Abraham (1987, 2000), Nóvoa (1992), Riegel (1979); Erikson (1989), Huberman (1989); pesquisa de cunho narrativo - Connelly; Clandinin (1995), Mcevan (1998), Bolivar, Domingo e Fernández (2001), Goodson (2004); análise textual discursiva - Moraes (2003), Moraes e Galiazzi (2007), Bauer e Gaskell (2004). Os procedimentos metodológicos versam sobre as análises narrativas dos processos de autorreconstrução biográfica, a pesquisa possui característica qualitativa de cunho narrativo, utilizou de entrevista narrativa, com os autores de base: tendo como sujeitos os professores atuantes em uma instituição pública, selecionados por critérios de estratificação, por tempo de docência e representação das áreas de conhecimento do CNPq (Exatas e da Terra, Biológicas, Saúde, Agrárias, Sociais e Aplicadas, Humanas, Linguística, Letras e Artes). As conclusões e resultados indicam que o conhecimento específico da área é a base sobre o qual é construída a pedagogia universitária. Esta se instaura no início da carreira docente como uma referência, moldando uma pedagogia configurada a partir de certo modo de pensar como se ensina e como se aprende. Existe uma convergência, portanto, tendo como referência, por um lado, o conhecimento específico e por outro os saberes acadêmicos, explicitados no exercício da docência e nas relações com o mundo do trabalho para o qual se direciona. As autoras apontam ainda três nós articuladores, quais sejam: 1) a pluralidade da pedagogia universitária, ou seja, existem tantas pedagogias universitárias quantas áreas diversificadas de conhecimento, uma pedagogia que vai sendo descoberta quando se enfrenta a incógnita de ensinar uma profissão, tarefa para a qual não houve preparação prévia - uma pedagogia do concreto - cuja forma e conteúdo vão se desvelando no enfrentamento da realidade, da educação e do mundo do trabalho, simultaneamente; 2) a tensão entre o conhecimento específico da área e o saber acadêmico pedagógico: Os saberes acadêmicos serão construídos no enfrentamento destas tensões e na constante busca de convergência entre os interesses da área específica e da área pedagógica. Segundo as autoras, surge a questão da [re] construção pedagógica do conhecimento científico, cuja modelagem tem, por um lado o progresso da área específica e, por outro, o mundo do trabalho, outro elemento tensionador; 3) o conhecimento pedagógico da área está imbricado na idéia de comunicação dos conteúdos específicos ao profissional em formação. O conhecimento da área específica e a 
sua [re] construção pedagógica na ação formadora constituem os saberes acadêmico. Segundo as autoras, os nós articuladores, presentes nas narrativas, indicam caminhos de pesquisa, como os movimentos construtivos da docência em contextos diversos de construção das diferentes pedagogias universitárias, explicitando e reconhecendo, pois, as peculiaridades próprias às áreas de conhecimento específico dos professores participantes e inferir como se articulam os conhecimentos específicos e os saberes acadêmicos no exercício da docência.

O trabalho intitulado As coreografias didáticas entre o presencial e o virtual e a [re]construção de novos saberes da Docência Superior, de Barbiero (2013) apresentam como objeto de estudo as repercussões das experiências de Docência Presencial - Dp e Docência Virtual - Dv na formação do professor universitário, envolvendo o estudo e as interinfluencias de coreografias Didáticas. Os referenciais teóricos de apoio versam sobre: entrevistas narrativas - Jovchelovitch e Bauer (2002), Análise Textual Discursiva - Moraes (2003); formação de professores - Francisco Imbernón (2006); Marcelo García (1999); espaço e lugar de formação - Cunha, (2008); Ambiência Docente - Maciel (2012); didática - Gil (2009), Masetto (1997); coreografias didáticas - Padilha et al. (2010); relação ao Saber Tardif (2000); conceito de docência - Isaia (2006); Cunha (2004, 2010); saberes da docência Tardif (2010), Gauthier (2010) e Cunha (2010); ambientes digitais de aprendizagem Almeida (2003); polidocência, - Mill (2012); conhecimento compartilhado e a aprendizagem colaborativa docente (BOLZAN, 2002); docência virtual compartilhada - Maciel e Siluk (2006).

Em relação aos procedimentos metodológicos: abordagem qualitativa, cunho narrativo e entrevistas narrativas com professores da Educação Superior. As conclusões e resultados indicam que as experiências de Dp e Dv interferem na formação do professor da educação superior, sendo estas experiências usadas pelos docentes como meio de avaliação e re-construção dos seus saberes. Ações institucionais, como as capacitações tecnológicas e cursos de formação continuada também agem na direção do desenvolvimento dos professores, porém, em relação à docência, estas não possuem a mesma intensidade. Sinalizam a importância em investir em mais ações voltadas para a criação de programas de formação e desenvolvimento profissional dos professores atuantes na Dp e na Dv. O autor indica também a experiência na Dv possibilitou aos docentes, o desenvolvimento dos seus saberes a partir de reflexões produzidas no desenho e na condução de aulas mediadas pelo Moodle; a Dp exige Coreografias Didáticas diferentes da Dv, devido às especificidades das modalidades 
educativas; os tutores a distância quanto os monitores são agentes na re - construção dos saberes docentes; as experiências na Dp e na Dv influem diretamente na formação dos professores, criando condições para a aprendizagem docente e a re-construção de saberes. $\mathrm{O}$ autor sinaliza ainda o compromisso de aprendizagem também pela instituição, na construção de uma ambiência (trans)formativa favorecendo as condições ao desenvolvimento profissional dos professores. A pesquisa indica ainda caminhos para mais questionamentos, envolvendo a complexidade assumida pela docência nas dimensões presencial-virtual e tecnológico-pedagógica.

Na $37^{\circ}$ Reunião da ANPEd realizado em 2015, 3 dos 34 trabalhos completos estão inseridos na temática Formação docente para a Educação Superior.

$O$ trabalho intitulado Tendências e implicações da formação continuada para a identidade profissional docente universitária, de Aguiar (2015), apresenta como objeto de estudo o contexto de formação continuada na universidade e de suas estruturas e modos de organização favorecem ou limitam os processos de (re)construção da identidade docente universitária. Os referenciais teóricos de apoio consistem em: formação da identidade Erikson (1976); crise da identidade docente - Lopes (2007); papéis docentes - Libâneo (2004); saberes e experiências diversas em relação formação docentes - Pacheco (1997); formação continuada no interior da universidade - Cunha (2004); docência universitária Zabalza (2004) , Cunha (2004), Bazzo (2005), Pimenta e Anastasiou (2005); identidade profissional - Dubar (1997); noções de formação - Ducoing (2007); conhecimento profissional docente - Roldão (2007); lógica de produção-construção de saber - Pacheco, Terrasêca e Caramelo (1999); formação contínua - Nóvoa (2001); núcleos temáticos - Bardin (1988); projeto de pedagogia Universitária De Par em Par - Pêgo et al. (s.a). Em relação aos procedimentos metodológicos, a pesquisa possui cunho qualitativo e teve como corpus de pesquisa os discursos dos professores, a partir de entrevista semiestruturada e de questionários. As conclusões e resultados indicam que a identidade profissional do professor se constrói sobre os saberes profissionais e sobre as atribuições de ordem ética. Recebe influências do contexto sociopolítico, cultura do grupo de pertença profissional. As análises e reflexões evidenciaram que as formações carecem ser repensadas para articular os saberes desenvolvidos por docentes, e por docentes e estudantes. A autora ressalta a importância dos suportes organizacionais necessários para o desenvolvimento profissional do docente universitário, pois, nestes espaços, o docente constrói seus laços com a instituição. Indica 
algumas alternativas para essas questões, como a criação de políticas e programas de formação, condições de trabalho para o docente e uma maior organização do trabalho pedagógico. Indica também que distintos interesses têm ocasionado mudanças que exigem a implantação de políticas de formação e de gestão que revelem compromisso para as universidades, embora, difícil de operacionalizar.

O trabalho intitulado Marcas e tensões no desenvolvimento profissional de professores do ensino superior, de Schnetzler, Cruz e Martins (2015), apresenta como objeto de estudo a identificação dos sentidos e significados elaborados pelos sujeitos, marcas e tensões do desenvolvimento profissional de professores universitários doutorandos em um programa de pós-graduação em educação. Os referenciais teóricos de apoio versam sobre: reforma universitária - Cury (2005); história da pós graduação na universidade - Machado e Bianchetti (2011), Bosi (2007), Kuenzer e Moraes (2005); o contexto da universidade Sguissardi e Silva Júnior (2009); o docente na universidade - Santos (2012); atividade docente - Schön (1983), Cunha (2010a), perspectiva histórico-cultural - Vigotski (1993); formação inicial do profissional - Zeichner (1993); formação de professores - Maldaner (2000); pluridimensionalidade dos percursos individuais - Oliveira, Rego e Aquino (2006); abordagem vigotskiana sobre o homem - Góes (2000); trabalho docente na universidade. Santos (2012); desenvolvimento profissional docente - Cunha et al. (2010); relação pesquisa e ensino na pós-graduação - Cunha (2010b) Em relação aos procedimentos metodológicos foi desenvolvida a análise de depoimentos, por meio da perspectiva histórico - cultural, pela questão "Por que ensino como ensino?", proposta em determinada disciplina. As conclusões e resultados evidenciam a importância atribuída pelos nossos sujeitos à sua formação inicial, que alicerçaram a sua iniciação na docência universitária, pelos desafios enfrentados nas suas trajetórias, questionaram-na, apreendendo com seus alunos e abrindo-se a mudanças nos seus fazeres docentes. A pesquisa indica ainda: a caminhada não contou com a ajuda de colegas, na formação de parcerias; buscaram a pós-graduação não somente pelos títulos, mas, principalmente, pela necessidade de melhorarem o seu fazer docente; a pós-graduação em educação é compreendida como espaço de desenvolvimento profissional docente, onde têm acesso a teorias educacionais que lhes possibilitam refletir sobre suas práticas docentes; a pósgraduação é o espaço de discussões e trocas experiência. As autoras indicam ainda a contradição preconizada por outros programas de pós-graduação em que há uma linear relação de qualidade entre a pesquisa. As análises indicam o cuidado de não operar 
dicotomias entre pesquisa e ensino no processo de desenvolvimento profissional docente, pois, para os sujeitos da pesquisa, a pós-graduação em educação, mesmo priorizando a formação do pesquisador, se configurou como lugar de produção de transformações em seus modos de ensinar. Observa-se que o desenvolvimento profissional de docentes universitários não está sendo promovido pelas IES nas quais os sujeitos trabalham, restando a eles buscá-lo por razões e motivos pessoais. Indicam ainda a necessidade urgente de criação de espaços e tempos de formação continuada de professores universitários institucionalmente propostos, e sugerem ainda um papel mais expressivo que programas de pós-graduação em educação possam vir a desempenhar em relação à promoção de desenvolvimento profissional de professores do ensino superior

O trabalho intitulado Profissionalidade docente: uma análise a partir das relações entre os professores e o contexto de trabalho no ensino superior, de Mussi e Almeida (2015), apresenta como objeto de estudo a compreensão das repercussões das relações dos docentes com a instituição de ensino para a produção dos saberes docentes. Os referenciais teóricos de apoio versam sobre: profissionalidade do professor Alves e André (2013), Ambrosetti e Almeida (2007), Roldão (2005), Tardif (2002), Sacristán (1995). Ramalho, Nuñez e Gauthier (2003), Dubar (1997), Tardif e Lessard (2007); docência no ensino superior - Gatti e Barreto (2009); análise de caso de ensino - Shulman (1992); descritores de profissionalidade - Roldão (2005); trabalho e identidade - Raymond e Tardif (2000) e Dubar (1997); trabalho e saberes docente - Roldão (2005), Tardif (2002); ensinar conteúdos Shulman (2005). Em relação aos procedimentos metodológicos a investigação de cunho qualitativa teve como sujeitos da pesquisa 15 professores que atuam em cursos da área da saúde de uma universidade pública baiana. A coleta foi realizada pela aplicação de questionários e casos de ensino. As conclusões e resultados indicam o empenho dos professores em desenvolver um trabalho consistente em sala de aula, muito embora encontrem grandes desafios para fazer face às mudanças no perfil sócio-cultural dos estudantes que chegam à universidade, com interesses muito imediatistas e com novas necessidades de aprendizagem, o que tem levado os professores a adequar suas práticas, rever seus saberes, para dar conta dessas novas demandas; a prática docente é uma importante via de produção dos saberes específicos, porém movimento de reconstrução dos saberes e práticas restringe-se, no entanto, ao âmbito das iniciativas individuais dos professores; as instituições de Ensino Superior não incorporam esses desafios em seus projetos institucionais, nem 


\section{OO DEVIR EDUCAÇÃO}

ISSN: 2526-849X

oferecem condições para a construção de um espaço coletivo de trabalho que favoreça a reflexão em torno das novas necessidades formativas; a necessidade das instituições de ensino superior e das políticas educacionais se atentarem para a promoção de espaços sistemáticos para a socialização; o contexto de trabalho no ensino superior indica que há uma carência em relação ao tempo para dar conta das atividades cotidianas necessárias; o reconhecimento social da especificidade da profissão aparece de forma fragmentada, prevalecendo o sentimento de desvalorização profissional, diante das condições de trabalho, salário e carreira; o saber específico da docência se pauta pelo domínio do conteúdo e se refere ao saber mais valorizado pelos docentes participantes da investigação; defender a autonomia do professor não significa valorizar a individualidade, e sim possibilitar espaços para a troca, socialização e revisão de teorias e práticas com vistas ao fortalecimento da autonomia; o sentimento de pertença a um corpo coletivo aparece de forma fragmentada nas relações dos docentes no contexto de trabalho. Por fim, as autoras indicam que os dados analisados permitem afirmar que um aspecto fundamental na construção da profissionalidade diz respeito ao próprio trabalho e a profissionalidade docente é resultante de um movimento dinâmico e complexo entre os saberes específicos e a ação dos professores, individual e coletiva, na condução de suas práticas laborais e as disposições dos contextos das instituições de ensino superior em que essas práticas se materializam.

\section{O que dizem as categorias}

Na categoria objeto de estudo, os trabalhos apresentam as temáticas relacionadas aos saberes docentes, as atividades inerentes ao trabalho docente, os processos formativos, a construção da identidade docente, as representações e significações dos docentes nas formações continuadas propostas pelas instituições a que fazem parte, as necessidades em relação aos processos formativos e aos aspectos profissionais, a formação pedagógica, marcas e tensões do desenvolvimento profissional em professores universitários doutorandos em um programa de pós-graduação em educação e a compreensão das repercussões das relações dos docentes com a instituição de ensino para a produção dos saberes docentes. 
Na categoria referenciais teóricos de apoio, em relação ao conceito de formação de professores, inicial ou continuada, destacam-se os seguintes autores: Cunha (2004), Feiman (1990), Francisco Imbernón (2006), García (1999), Kessler (2002), Maldaner (2000), Marcelo García (1999), Nóvoa (2001, 2009), Pimenta e Anastasiou (2010), Sacristán (1990), Schön (2000), Veiga (1991, 1993, 2002, 2006, 2010), Zeichner (1993).

Destacamos que ao analisar as referências indicadas ao final de cada trabalho, alguns autores apresentam o maior número de obras citadas, sendo base conceitual em diferentes aspectos. Apresentamos a seguir os dois autores com o maior número de obras referenciadas, quais sejam: Maria Izabel da Cunha, com 18 obras, e Maurice Tardif, com 10 obras.

A autora Maria Izabel da Cunha conta com 18 indicações, em diferentes publicações (artigos, livros etc.), nas referências dos trabalhos, tanto como autora principal quanto citação individual. Suas obras referenciam os conceitos: de docência na universidade e seu contexto, atividade docente, conceito e concepção de docência, contexto da docência universitária, da Pedagogia Universitária, e os dilemas que nelas se encontram, contexto da universidade sobre práticas conservadoras, desenvolvimento profissional docente, docência na Educação Superior e na universidade, formação continuada no interior da universidade, função da docência na universidade e formação docente para a universidade, o docente do Ensino Superior, o professor universitário, práticas de avaliação na pós-graduação, relação pesquisa e ensino na pós-graduação, saberes da docência, sobre o ensino e o processo de ensinar.

O autor Maurice Tardif aparece com 10 indicações de obras, sendo que destas, quatro são obras publicadas em conjunto com o autos Claude Lessard, suas obras referenciam os conceitos de relação com o saber, docência universitária, os professores, seus saberes e trajetória profissional, profissionalidade do professor, saberes da docência, sobre a prática docente e o trabalho docente, universidade - conceito de ensinar.

$\mathrm{Na}$ categoria procedimentos metodológicos a maioria das pesquisas indicou ser de natureza qualitativa, utilizando-se dos seguintes instrumentos de coleta de dados: entrevista narrativa, questionário, observação das atividades, casos de ensino e narrativas. Entre as 11 pesquisas, 6 pesquisas $(54,5 \%)$ utilizaram apenas um instrumento para coleta de dados, sendo estas narrativas, entrevistas, questionários, casos de ensino e análise de depoimento, predominando a entrevista como método adotado; 3 pesquisas $(27,3 \%)$ utilizaram 2 instrumentos e apenas 1 pesquisa $(9,0 \%)$ valeu-se de três instrumentos para a coleta de dados. 
Ressaltamos ainda que não foi possível o acesso ao texto completo de um trabalho 1 apresentado, dentre os 11 trabalhos analisados.

A categoria conclusões e resultados indica que a maioria dos trabalhos analisados direciona o olhar para o docente universitário em início de carreira, bem como a construção, definição, sentidos e significados relacionados aos saberes da docência, a profissionalidade, desenvolvimento e trabalho do docente. Entre as diversas lacunas apresentadas, destaca-se o pouco incentivo e desenvolvimento de ações de formação em serviço do docente no Ensino Superior, em que seja proporcionado um espaço de compartilhamento, discussões e reflexão.

Destacamos o surgimento de duas categorias a priori após a leitura e análise das pesquisas, quais sejam: sujeitos da pesquisa e instituição, indicadas a seguir.

Constituíram os sujeitos da pesquisa professores do Ensino Superior, PósGraduandos e docentes universitários desenvolvendo o doutorado. Entre as 11 pesquisas analisadas, 9 pesquisas, ou seja, 81,9\%, os sujeitos eram os professores do Ensino Superior, em diferentes períodos da vida profissional (iniciante, intermediário e final); 1 pesquisa 9,0\% - referia-se aos pós-graduandos e 1 pesquisa $(9,0 \%)$ referia-se aos docentes universitários desenvolvendo o doutorado.

Na categoria instituição, estão presentes 6 universidades, quais sejam: Universidade Federal de Santa Maria (UFSM), Universidade Federal de Pernambuco (UFPE), Universidade federal de Uberlândia (UFU), Universidade Federal de São Carlos (UFSCar); Universidade Metodista de Piracicaba(UNIMEP) e Universidade Estadual de Feira de Santana do Estado da Bahia (UEFS). Entre os 11trabalhos analisados, 4 (36,4\%) são da UFSM, 3 (27,3\%) da UFPE, e com 1 trabalho cada (9,0\% cada.) UFSCar, UNIMEP, UEFS e UFU. Nesta categoria duas universidades federais apresentam a concentração de estudos na área da formação docente para a Educação Superior, no período de 2011 a 2017: UFSM e UFPE.

\section{Conclusão}

As pesquisas analisadas, apresentadas no GT8 - Formação de Professores, na ANPEd, no período de 2011 a 2017, relacionadas ao tema Formação Docente para a Educação Superior, sinaliza para um campo de pesquisa que proporciona uma vasta área para 
investigação científica. Ressaltamos ainda que a análise versou apenas sobre os trabalhos completos apresentados na ANPEd, sinalizando a importância de estudos que referenciem os demais meios de divulgação científica da ANPEd, como pôsteres, trabalhos encomendados etc., proporcionando uma visão ainda mais ampla sobre o contexto da pesquisa em formação docente para a Educação Superior.

No universo de 115 trabalho, apenas 11, ou seja 9,6\% dos trabalhos se referiram ao tema indicado e este dado revela uma ausência de produções ou até mesmo publicações de pesquisa científicas voltadas para a formação inicial, em nível de pós-graduação, de professores para a docência na Educação Superior. As pesquisas analisadas apresentam diversos objetos de estudo, porém a maioria é direcionada ao sujeito docente no contexto da universidade, revelando a importância em pensar a formação continuada a partir das necessidades deste docente em serviço. Os instrumentos para a coleta de dados concentram-se na utilização de entrevista, destacando-se a entrevista de cunho narrativo, seguindo do questionário. Em relação a temática formação de professores há uma diversificação dos referenciais teóricos de apoio, indicando predominância de determinados autores para diferentes conceitos

Os dados analisados mostram que a discussão sobre a formação docente para o Educação Superior está praticamente ausente no GT 08 - Formação de Professores, em relação aos trabalhos completos apresentados na ANPEd no período de 2011 a 2017, se comparada aos demais temas abordados, relacionados principalmente à formação de professores para a Educação Básica. Neste contexto, este artigo fomenta a discussão sobre a área de pesquisa relacionada ao tema da formação de professores para a Educação Superior, indicando possíveis caminhos e lacunas para pesquisas posteriores nesta área de conhecimento, como ampliar a aprofundar as pesquisas sobre os professores universitários em início de carreira, os sentidos e significados dados ao anos inicias da docência, bem como voltar o olhar às iniciativas institucionais para a formação docente em serviço, incluindo também as instituições privadas. É relevante considerar também a ampliação e aprofundamento das pesquisas sobre a formação docente para o Ensino Superior no contexto da pós-graduação, na perspectiva do estudante em nível de mestrado e doutorado, pois estas configuram-se ainda como terreno fértil de pesquisas na área.

\section{Referências}

Revista Devir Educação, Lavras, vol.3, n.2, p.53-74 jul./dez., 2019. 
AGUIAR, Maria da Conceição Carrilho de. Tendências e implicações da formação continuada para a identidade profissional docente universitária. In: $37^{\circ}$ REUNIẪO CIENTÍFICA DA ANPED, 37. 2015, Florianópolis. Anais. Florianópolis: GT08 - Formação de Professores, 2015, p.1-16.

BARBIERO, Danilo Ribas. As coreografias didáticas entre o presencial e o virtual e a [re]construção de novos saberes da Docência Superior. In: $36^{\circ}$ REUNIÃO CIENTÍFICA DA ANPED, 36. 2013, Goiânia. Anais. Goiânia: GT08 - Formação de Professores, 2013, p.1-19.

BOGDAN, Robert; BICKLEN, Sari Knopp. Investigação qualitativa em educação. Porto: Porto, 1997.

BRASIL. Lei 9394/96, de 20 de dezembro de 1996. Lei de diretrizes e bases da educação nacional. 1996. Disponível em: <http://www.planalto.gov.br/ccivil_03/leis/L9394.htm>. Acesso em: 25 jun. 2015.

CAMPOS, Vanessa Therezinha Bueno. Formar ou preparar para a docência no ensino superior? eis a questão. In: $35^{\circ}$ REUNIÃO CIENTÍFICA DA ANPED, 35. 2012, Porto de Galinhas. Anais. Porto de galinhas: GT08 - Formação de Professores, 2012, p.1-14.

CELLARD, André. A análise documental. In: POUPART, J. et al. A pesquisa qualitativa: enfoques epistemológicos e metodológicos. Petrópolis: Editora Vozes, 2008, p. 295-315.

CUNHA, Maria Isabel. Os conceitos de espaço, lugar e território nos processos analíticos da formação dos docentes universitários. Revista Educação Unisinos, São Leopoldo. RS, v. 12, n. 3, p. 182-186, set./dez. 2008.

MINAYO, Maria. Cecília de Souza. (Org.). Pesquisa social: teoria, método e criatividade. 29. ed. Petrópolis: Vozes, 2010.

FERRAZ, Bruna Tarcilia; MELO, Márcia Maria de Oliveira. Docência Universitária na Pós-Graduação: situando efeitos da Avaliação da Capes na Profissionalidade. In: $35^{\circ}$ REUNIÃO CIENTÍfICA DA ANPED, 35. 2012, Porto de Galinhas. Anais. Porto de Galinhas: GT08 - Formação de Professores, 2012, p.1-17.

ISAIA, Silvia Maria de Aguiar; MACIEL, Adriana Moreira da Rocha. Pedagogia Universitária: construções possíveis nas Diferentes áreas de conhecimento. In: $36^{\circ}$ REUNIÃO CIENTÍFICA DA ANPED, 36. 2013, Goiânia. Anais. Goiânia: GT08 - Formação de Professores, 2013, p.1-17.

LIMA, Emília Freitas Análise de necessidades formativas de docentes ingressantes numa universidade pública. In: $36^{\circ}$ REUNIÃO CIENTÍFICA DA ANPED, 36. 2013, Goiânia. Anais. Goiânia: GT08 - Formação de Professores, 2013, p.1-17.

MUSSI, Amali de Angelis; ALMEIDA, Elisa Carneiro Santos de. Profissionalidade docente: uma análise a partir das relações entre os professores e o contexto de trabalho no 


\section{OD DEVIR EDUCAÇÃO \\ ISSN: 2526-849X}

ensino superior. In: $37^{\circ}$ REUNIÃO CIENTÍFICA DA ANPED, 37. 2015, Florianópolis. Anais. Florianópolis: GT08 - Formação de Professores, 2015, p. 1-17.

OLIVEIRA, Valeska Maria Fortes. Docência Universitária e o Ensino Superior: análise de uma experiência formadora. In: 34 REUNIÃO CIENTÍFICA DA ANPED, 34. 2011, Natal. Anais. Natal: GT08 - Formação de Professores, 2011, p.1-17.

POWACZUK, Ana Carla; BOLZAN, Doris Pires Vargas. Atividades de produção da docência: a professoralidade Universitaria. In: $34^{\circ}$ REUNIÃO CIENTÍFICA DA ANPED, 34. 2011, Natal. Anais. Natal: GT08 - Formação de Professores, 2011, p.1-16.

ROCHA, Áurea Maria Costa; AGUIAR, Maria da Conceição Carrilho de. Aprender a ensinar, construir identidade e profissionalidade docente no contexto da universidade: uma realidade possível. In: $35^{\circ}$ REUNIÃO CIENTÍFICA DA ANPED, 35. 2012, Porto de Galinhas. Anais. Natal: GT08 - Formação de Professores, 2011, p.1-17.

SEVERINO, Antônio Joaquim. Metodologia do Trabalho Científico. 23.ed. São Paulo: Cortez, 2007.

SCHNETZLER, Roseli Pacheco; CRUZ, Maria Nazaré da; MARTINS, Ida Carneiro. Marcas e tensões no desenvolvimento profissional de professores do ensino superior, In: $37^{\circ}$ REUNIÃO CIENTÍFICA DA ANPED, 37. 2015, Florianópolis, Anais. Florianópolis: GT08 - Formação de Professores, 2015, p.1-16. 